\title{
HUBUNGAN POTENSI ANTARA CENDAWAN MIKORIZA ARBUSKULA DAN SIFAT-SIFAT TANAH DI LAHAN KRITIS
}

\author{
The Relationship Between Arbuscular Mycorrhizal Fungi Potency and Soil Properties in \\ Marginal Land
}

\author{
Ishak Yassir dan R. Mulyana Omon \\ Loka Litbang Satwa Primata Samboja
}

\begin{abstract}
The research on relationship between Arbuuscular Mycorrhizal Fungi (AMF) with chemical and physical soil characteristics on marginal land were conducted in Samboja Lestari rehabilitation area at Km.35, East Kalimantan. The objective of the research was to know correlation between physical and chemical characteristics and AMF potential on marginal land. The experiment used a single method based on topography and floristic composition. Every condition of the topography (hill top, slope and valley) were sampled by provided of 5 sample plots, each $10 \mathrm{~m} \times 10 \mathrm{~m}$. Within these plots there were randomly smaller plot of $1 m \times 1 m$ with three times replication. Therefore, the total number at observation plots were $3 \times 5 x$ $3=45$ plots. The results showed that the general soil condition in this area is poor with the soil $p H(4,5)$, C-organic (21,55\%), N total $(0,13 \%)$, available $P(498 \mathrm{ppm})$, available $K(0,44 \mathrm{me} / \mathrm{g})$ and CEC $(8,99 \mathrm{me}$ / $100 \mathrm{~g}$ ). The density of spores potency is good, with the number of spores $1288-2321 / 50 \mathrm{~g}$ soil in dry season and during the wet season as many as $1274-2163$ spores $/ 50 \mathrm{~g}$ soil, from the genera Glomus, Acaulospora and Gigaspor. While correlatiion between AMF potency and soil physical and chemical is depened on available $P$. There was a negative correlation between the number of spores and the $P$ available, which is indicated by number of spores were tend to less by the increase of available $P$ in the soil.
\end{abstract}

Key words: Arbuscula mycorrhiza fungi, marginal land

\begin{abstract}
ABSTRAK
Penelitian tentang hubungan antara Cendawan Mikoriza Arbuskula (CMA) dengan sifat-sifat fisik dan kimia tanah pada lahan kritis telah dilakukan di areal rehabilitasi Samboja Lestari Km 35, Kalimatan Timur. Tujuan penelitian ini adalah untuk mengetahui hubungan antara sifat-sifat fisik dan kimia tanah terhadap potensi CMA pada lahan kritis. Percobaan ini dilakukan dengan menggunakan metoda petak tunggal berdasarkan letak topografi dan komposisi tumbuhan. Pada setiap kondisi topografi (puncak, lereng dan lembah) dibuat petak yang berukuran $10 \mathrm{~m}$ x $10 \mathrm{~m}$ masing-masing sebanyak 5 buah petak. Di dalam petak berukuran $10 \mathrm{~m} \times 10 \mathrm{~m}$ dibuat petak berukuran $1 \mathrm{~m} \times 1 \mathrm{~m}$ yang ditempatkan secara acak dan diulang sebanyak 3 kali. Jumlah petak yang diamati seluruhnya sebanyak $3 \times 5 \times 3=45$ buah petak. Hasil penelitian menunjukkan bahwa kondisi tanah di lokasi penelitian secara umum tidak subur, yang ditunjukkan dengan $\mathrm{pH}$ tanah yang masam $(4,32)$, bahan organik yang rendah sampai dengan sedang, yaitu C-organik $(2,15 \%)$, kandungan $\mathrm{N}$ total $(0,13 \%) \mathrm{P}$ tersedia (498 ppm), K tersedia $(0,44 \mathrm{me} / \mathrm{g})$ dan KTK $(8,99 \mathrm{me} / 100 \mathrm{~g})$. Kepadatan spora CMA cukup baik, dengan jumlah 1288-2321 spora/50 g pada bulan kering dan pada bulan basah 1274-2163 spora/50 g tanah, dari genus Glomus, Acaulospora dan Gigaspora. Untuk hubungan antara potensi CMA dengan sifat-sifat tanahnya sangat ditentukan oleh kandungan $P$ tersedia, dan terjadi korelasi negatif antara jumlah spora dengan kandungan $P$ tersedia, yang ditunjukkan oleh jumlah spora CMA yang menurun selaras dengan meningkatnya kandungan $P$ tersedia di dalam tanah.
\end{abstract}

Kata kunci: Cendawan mikoriza arbuskula, lahan kritis 


\section{PENDAHULUAN}

Pemerintah cq. Departemen Kehutanan saat ini sedang menggalakkan program GNRHL (Gerakan Nasional Rehabilatasi Hutan dan Lahan), yaitu gerakan penanaman secara nasional dengan menanam berbagai jenis tanaman kehutanan pada lahan-lahan kritis yang telah mengalami kerusakan fisik tanah karena berkurangnya penutupan vegetasi dan adanya gejala erosi, yang akhirnya membahayakan fungsi hidrologi dan lingkungannya (Sunyoto et al. 1993). Badan Planologi Kehutanan (2002) melaporkan di Indonesia terdapat 96.3 juta hektar lahan yang perlu direhabilitasi dan diperkirakan akan terus meningkat setiap tahunnya, jika tidak ada upaya untuk merehabilitasinya. Dalam rangka mendukung kegiatan rehabilitasi yang ditujukan pada lahan-lahan kritis penggalian informasi tentang potensi Cendawan Mikoriza Arbuskula (CMA) dan keterkaitannya dengan sifat-sifat tanah penting untuk dilakukan. Hal ini dikarenakan CMA efektif dalam meningkatkan penyerapan unsur hara, memperbaiki stabilitas/struktur tanah (Jeffries \& Dodd, 1991), meningkatkan daya tahan tanaman terhadap beberapa penyakit akar (Jalali B. \& Jalali I., 1991), mampu meningkatkan toleransi tanaman terhadap kekeringan juga faktor pengganggu lain seperti salinitas tinggi, logam berat dan ketidakseimbangan hara (Paulitz \& Linderman, 1991), serta berperan dalam pembentukan komunitas tanaman (Koide \& Mosee, 2004).

Sehubungan dengan hal tersebut perlu dilakukan penelitian untuk mendapatkan informasi tentang hubungan antara potensi CMA dengan sifat-sifat tanah di lahan kritis (alang-alang) di areal rehabilitsi Samboja Lestari, dengan tujuan untuk mengetahui sifat fisik dan kimia tanah yang dapat mempengaruhi potensi CMA pada lahan kritis. Penelitian ini sangat penting untuk dilakukan, berkaitan dengan pernyataan Mansur et al. (2002) yang mengemukakan bahwa hampir 70\% kegiatan penelitian CMA diarahkan pada manfaatnya dalam pertumbuhan tanaman dan kurang dari $15 \%$ yang mempelajari keanekaragaman CMA pada suatu ekosistem atau tegakan. Berdasarkan hal tersebut di atas, diharapkan hasil penelitian dapat memberikan informasi tambahan dan bermanfaat dalam merehabilitasi areal terdegredasi yang ditumbuhi oleh alang-lalang.

\section{BAHAN DAN METODE}

\section{A. Tempat dan Waktu Penelitian}

Penelitian dilaksanakan di areal Yayasan Penyelamatan Orangutan Borneo di Desa Sie Merdeka, Kecamatan Samboja, Kabupaten Kutai Kartanegara, Propinsi Kalimantan Timur. Lokasi penelitian terletak di Km. 35 dari arah Balikpapan menuju ke Samarinda. Penelitian dilaksanakan mulai bulan Agustus 2004 sampai dengan bulan Januari 2005.

Lokasi penelitian yang dijadikan petak coba mempunyai topografi bergelombang dengan topografi datar sampai dengan berbukit dan kelerengan berkisar antara $0^{\circ}-35^{\circ}$ serta berada pada ketinggian antara $70 \mathrm{~m}$ sampai $150 \mathrm{~m}$ dpl. Secara umum $\mathrm{pH}$ tanah sangat masam sampai masam, kadar $\mathrm{C}$ sangat rendah sampai sedang, kadar $\mathrm{N}$ sangat rendah sampai rendah, $\mathrm{P}$ sangat rendah, $\mathrm{K}$ rendah sampai tinggi, kapasitas tukar kation sangat rendah sampai rendah, tekstur tanahnya sebagian besar bertekstur liat dan sebagian kecil bertekstur pasiran, dengan didominasi jenis tanah podsolik merah kuning.

Data curah hujan dan temperatur yang diperoleh dari statsiun pengamatan cuaca di lokasi Yayasan BOS-Samboja Lestari dan berdasarkan klasifikasi Schmidt dan Ferguson (1951), daerah penelitian termasuk tipe iklim B, dengan curah hujan rata-rata tahunan berkisar antara $2700 \mathrm{~mm} 2850 \mathrm{~mm}$ dengan rata-rata hari hujan antara $10-15$ hari. Temperatur rata-rata bulanan antara $23^{\circ}-31^{\circ} \mathrm{C}$, dengan periode musim hujan dan kemarau yang tidak jelas. Bulan kering umumnya terjadi pada bulan Juli - Agustus dan bulan basah mulai bulan November - Mei. 


\section{B. Bahan}

Bahan yang dijadikan penelitian adalah lahan yang telah tergreadasi yang umumnya didominir alang-alang. Areal ini Yayasan BOS Samboja Lestari diperuntukkan sebagai salah satu program rehabilitasi lahan yang ditanami tanaman buah-buahan dan tanaman kehutanan.

\section{Metode}

Didalam pembuatan petak-petak penelitian telah dilakukan survey lapangan terlebih dahulu untuk penentuan lokasi yang akan dijadikan petak contoh dengan cara penentuan sebagai berikut:

\section{Penentuan petak}

Petak contoh dibuat dengan metode 'releve' (Mueller-Dombois \& Ellenberg, 1974) atau metode petak tunggal (Soerianegara \& Indrawan, 1998). Pembuatan jumlah petak contoh didasari dengan mempertimbangkan kondisi topografi dan komposisi floranya. Berdasarkan pendekatan ini kemudian dipilih dan ditetapkan sebanyak 15 petak contoh primer (primary unit) yang masing-masing berukuran $10 \mathrm{~m} \times 10 \mathrm{~m}$. Dari 15 petak contoh primer tersebut pada masing-masing topografi dibuat 5 petak contoh di puncak, lereng dan lembah. Selanjutnya di dalam satuan petak contoh primer tersebut dibuat petak-petak contoh sekunder yang lebih kecil (secondary unit) dengan ukuran $1 \mathrm{~m}$ x1 m sebanyak 3 buah. Jadi jumlah keseluruhan petak contoh sebanyak $3 \times 15=45$ buah petak contoh sekunder. Petak contoh sekunder diletakkan secara acak pada petak-petak contoh primer.

\section{Analisis tanah}

Pada setiap satuan-satuan unit contoh primer (primary unit) dilakukan pengambilan contoh tanahnya. Pengambilan contoh tanah dilakukan pada setiap petak contoh dengan kedalaman $0 \mathrm{~cm}-10$ $\mathrm{cm}$ dan $10 \mathrm{~cm}-30 \mathrm{~cm}$. Setiap contoh tanah dianalisis beberapa sifat fisika dan kimianya, yaitu kandungan pasir, debu, liat, berat volume tanah, $\mathrm{pH}$ tanah, $\mathrm{C}$ organik, kandungan $\mathrm{N}$ total, $\mathrm{P}$ tersedia, $\mathrm{K}$ tersedia, kadar air, kapasitas tukar kation (KTK), $\mathrm{H}$ dan $\mathrm{Al}$ di Laboratorium Universitas Gajah Mada, Yogyakarta.

\section{Kelimpahan dan identifikasi}

Untuk menghitung kelimpahan mikoriza dilakukan dengan teknik mengekstrak spora CMA dengan cara tuang-saring berdasarkan metode Pacioni (1992) dan dilanjutkan dengan teknik sentrifugasi berdasarkan metode Brundrett et al. (1996). Prosedur tuang-saring adalah mencampurkan tanah sampel sebanyak 50 gr dengan 200-300 ml air dan diaduk sampai butiran-butiran tanah hancur, kemudian disaring dalam satu set saringan yang berukuran $250 \mu \mathrm{m}, 125 \mu \mathrm{m}$ dan $45 \mu \mathrm{m}$ secara berurutan dari atas ke bawah.

Teknik tuang-saring kemudian dilanjutkan dengan ekstraksi spora melalui teknik sentrifugasi dan hasil saringan kemudian ditambahkan dengan larutan glukosa $60 \%$ yang diletakkan pada bagian bawah dari larutan tanah dengan mempergunakan pipet. Selanjutnya, larutan dimasukan ke dalam tabung sentrifuse dan ditutup rapat, disentrifuse dengan kecepatan 2500 rpm selama 3-5 menit. Larutan supernatant dituang ke dalam saringan $45 \mu \mathrm{m}$ dan dicuci dengan air untuk menghilangkan glukosa. Endapan yang tersisa dalam saringan di atas dituangkan ke dalam cawan petri dan diamati dengan menggunakan mikroskop untuk melihat kelimpahan spora. Kelimpahan spora CMA dilakukan pada bulan kering (musim kemarau) dan bulan basah (musim hujan), dengan tujuan melihat dan membandingkan jumlah kelimpahan spora CMA antara kedua musim tersebut.

Pembuatan preparat spora untuk identifikasi sampai tingkat genus mempergunakan bahan pewarna Melzer's dan pengawet PVLG yang diletakkan secara terpisah pada kaca preparat. Spora-spora CMA yang diperoleh dari ekstraksi setelah dihitung jumlahnya diletakan dalam larutan Melzer's dan PVLG. Spora-spora tersebut dipecahkan secara hati-hati dengan cara menekan kaca penutup preparat menggunakan ujung lidi. Perubahan warna spora dalam larutan Melzer's adalah salah satu indikator untuk menentukan tipe spora yang ada. 


\section{Analisis Data}

\section{Analisis diskriptif}

Analisis diskriptif dilakukan dalam penelitian ini untuk mencari nilai rata-rata peubah sifat-sifat fisik dan kimia tanah.

\section{Matrik Korelasi}

Matrik Korelasi dalam penelitian dilakukan untuk mengetahui dan menganalisa hubungan linear antar peubah-peubah ekologis yang telah dikumpulkan yang meliputi jumlah jenis dan populasi tumbuhan, jumlah spora CMA, sifat fisik dan kimia tanah pada lokasi penelitian. Pembuatan matrik korelasi ini dilakukan dengan Program SPSS 10.0 for Window, sedangkan uji korelasi yang digunakan adalah uji korelasi Pearson.

\section{HASIL DAN PEMBAHASAN}

\section{A. Sifat Fisika dan Kimia Tanah}

Hasil analisis beberapa sifat fisika dan kimia tanah dari petak contoh yang ada di lokasi penelitian disajikan pada Tabel 1. Berdasarkan Tabel tersebut secara umum bahwa tanah di lokasi penelitian relatif tidak subur, yang dicirikan dengan $\mathrm{pH}$ tanah yang masam, bahan organik yang rendah, kandungan hara yang rendah, KTK yang rendah dan sebagian besar tanah bertekstur liat dan sebagian kecil bertekstur pasiran. Kondisi tanah seperti ini pada umumnya merupakan ciri-ciri tanah bertipe ultisol (Pedsolik Merah Kuning). Mackinnon et al. (2000) melaporkan sebagian besar tanah di Kalimantan berkembang pada dataran bergelombang dan pegunungan yang tertoreh di atas batuan sedimen dan batuan beku tua. Tanah-tanah ini berkisar dari ultisol dan inceptisol muda. Hardjowigeno (1993) memberikan ciri bahwa pada umumnya tanah ultisol memiliki pelindian (leaching) yang tinggi, sehingga tanah bereaksi masam. Sebagai akibatnya tanah dengan tipe ini memiliki kandungan kadar bahan organik rendah, kejenuhan basa rendah, kapasitas tukar kation rendah, kadar hara rendah dan kemasaman tinggi. Karena basa-basa telah tercuci habis maka komplek pertukaran dijenuhi oleh Al dan Fe. Sarief (1986) menambahkan bahwa tanah bertipe ini juga memiliki sifat fisik yang tidak mantap dengan stabilitas agregat yang kurang baik, akibatnya tanah ini mudah terkena erosi akibat gerakan air. Struktur tanah cukup baik akan tetapi tidak mantap dengan kandungan mineral liatnya didominasi oleh kelompok kaolinit yang memiliki daya serap rendah, luas efektif sempit, air tidak dapat menyusup, sehingga jumlah air yang tersedia bagi tanaman relatif rendah.

Tabel 1. Hasil analisis fisik dan kimia tanah di petak contoh sebagai peubah

\begin{tabular}{|l|l|l|}
\hline \multicolumn{1}{|c|}{ Peubah } & Rataan & Keterangan* \\
\hline $\mathrm{pH}\left(\mathrm{H}_{2} \mathrm{O}\right)$ & $4.32 \pm 0.23$ & Sangat rendah \\
C-Organik & $2.15 \pm 0.96$ & Rendah s/d Sedang \\
Jumlah N (\%) & $0.13 \pm 0.03$ & Sangat rendah \\
P tersedia (ppm) & $4.98 \pm 2.48$ & Sangat rendah \\
K tersedia (me/100 g) & $0.44 \pm 0.22$ & Sedang \\
KTK (me/100 g) & $8.99 \pm 1.84$ & Sangat rendah \\
Liat (\%) & $20.6 \pm 7.45$ & \\
Debu (\%) & $37.9 \pm 10.2$ & \\
Pasir (\%) & $41.5 \pm 16.6$ & \\
\hline
\end{tabular}

*) Menurut kriteria Pusat Penelitian Tanah Bogor (Hardjowigeno, 1993). 


\section{B. Potensi Cendawan Mikoriza Arbuskula}

Perhitungan jumlah spora/50 gr tanah yang terdapat pada keseluruhan petak contoh primer dilakukan pada bulan Agustus 2004 (bulan kering) dan bulan Januari 2005 (bulan basah). Rata-rata jumlah spora/50 gr tanah di lokasi penelitian cukup bervariasi, yaitu antara 755-3813 spora/50 gr tanah. Adapun rata-rata jumlah spora pada masing-masing petak contoh disajikan pada Tabel 2 .

Berdasarkan Tabel 2 jumlah rata-rata spora pada bulan kering sebanyak 1805 spora/50 gr tanah dan pada bulan basah rata-rata sebanyak 1718 spora/50 gr tanah. Akan tetapi pada petak 5 dan 6 menunjukkan bahwa jumlah spora lebih tinggi dibandingkan petak-petak lainnya. Perbedaan ini dikarenakan pada petak 5 dan 6 terdapat populasi tumbuhan bawah lebih banyak dibandingkan dengan petak lainnya, yaitu disebabkan dengan perakaran yang sangat banyak dan ditambah kandungan $P$ tersedia di bagian lembah dan lereng $P$ tersedianya lebih tinggi. Pengaruh aliran permukaan akibat hujan yang secara bersamaan membawa lapisan topsoil yang didalamnya terdapat spora dari bagian puncak dan lereng menuju bagian lembah.

Tabel 2. Rataan jumlah spora/50 g tanah berdasarkan topografi di petak contoh

\begin{tabular}{|c|l|c|c|c|}
\hline \multirow{3}{*}{ Petak contoh } & Topografi & \multicolumn{2}{|c|}{ Waktu Pengamatan } & \multirow{2}{*}{ Rata-rata } \\
\cline { 3 - 4 } & & Musim kering & Bulan basah & \\
\hline 1 & Puncak & 923 & 1457 & 1190 \\
2 & Lereng & 1185 & 1106 & 1146 \\
3 & Puncak & 581 & 928 & 755 \\
4 & Lereng & 1599 & 1298 & 1448 \\
5 & Lembah & 3668 & 2776 & 3222 \\
6 & Lereng & 3862 & 3763 & 3813 \\
7 & Lembah & 1471 & 2297 & 1884 \\
8 & Lembah & 1860 & 1909 & 1885 \\
9 & Puncak & 1129 & 960 & 1044 \\
10 & Lereng & 1157 & 899 & 1028 \\
11 & Puncak & 1609 & 2373 & 1991 \\
12 & Lembah & 2392 & 1082 & 1737 \\
13 & Lereng & 1546 & 1651 & 1599 \\
14 & Puncak & 2365 & 1539 & 1952 \\
15 & Lembah & 1727 & 1742 & 1735 \\
\hline & Jumlah & 27074 & 25778 & 26429 \\
\hline & Rata-rata & 1805 & 1718 & 1762 \\
\hline
\end{tabular}

Berdasarkan karakteristik spora yang terdiri dari bentuk, ukuran, tebal dinding dan warna dalam larutan PVLG dan MELZER, CMA telah dijumpai jenis CMA dari genus Glomus, Acaulospora dan Gigaspora. Kehadiran dari CMA ini berkaitan erat dengan faktor lingkungan, iklim dan penggunaan lahan. Hal ini sesuai dengan pernyataan dari Bagyaraj (1991) yang mengemukakan bahwa genus Glomus mempunyai distribusi penyebaran yang sangat luas. Penyebaran yang luas berhubungan dengan keanekaragaman Glomus yang tinggi. Bagyaraj (1991) menyebutkan penyebaran genus Gigaspora secara umum dapat ditemukan pada tanah-tanah tropik terutama pada daerah perbukitan yang berpasir dan Acaulospora lebih beradaptasi pada tanah-tanah masam dengan $\mathrm{pH}<5$ sedangkan INVAM (2003) melaporkan hasil indentifikasi dari 172 jenis CMA, Glomus merupakan jenis yang paling dominan (52.3\%), diikuti Acaulaspora (20.9\%), Scutellospora (16.9\%), Gigaspora (4.7\%), Entrophospora (2.3\%), Archaeospora (1.7\%) dan Paraglomus (1.2\%). 


\section{Analisis Keterkaitan}

Hasil analisa terhadap jumlah spora dengan beberapa sifat fisik dan kimia tanah tiap petak percobaan selanjutnya diolah dengan mempergunakan uji korelasi Pearson untuk mengetahui keterkaitannya antar peubah tersebut. Berdasarkan hasil uji korelasi antara jumlah spora dengan sifatsifat tanah diperoleh hasil seperti tersaji pada Tabel 3.

Tabel 3.Nilai korelasi sifat-sifat tanah terhadap jumlah spora di petak contoh

\begin{tabular}{|c|l|c|c|}
\hline No. & \multicolumn{1}{|c|}{ Peubah } & Nilai korelasi (r) & Nilai-P \\
\hline 1 & Topografi & 0.37 & 0.18 \\
2 & $\mathrm{pH}: \mathrm{H}_{2} \mathrm{O}$ & 0.25 & 0.37 \\
3 & air & 0.41 & 0.13 \\
4 & $\mathrm{C}(\%)$ & -0.09 & 0.76 \\
5 & N total (\%) & 0.30 & 0.28 \\
6 & P tersedia (ppm) & $-0.55^{*}$ & 0.04 \\
7 & K tersedia (me/100 g) & 0.001 & 0.99 \\
8 & KTK (me/100g & 0.11 & 0.69 \\
9 & Liat & 0.39 & 0.15 \\
10 & Deebu & 0.04 & 0.90 \\
11 & Pasir & -0.19 & 0.49 \\
\hline
\end{tabular}

*) Keterangan: korelasi nyata pada taraf 5\%

Tabel 3 terlihat adanya korelesai negatif yang menunjukkan bahwa ketersedian $P$ tersebut berkorelasi negatif dengan jumlah spora. Mattjik dan Sumertajaya (2000) mengemukakan bahwa penggunaan koefisien korelasi untuk menggambarkan tingkat keeratan hubungan linier antara dua peubah atau lebih, besaran dari nilai koefisien korelasi tidak menggambarkan hubungan sebab akibat antara dua peubah atau lebih tetapi semata-mata menggambarkan keterkaitan liner antar peubah. Koefisien korelasi yang sering dinotasikan dengan $r$ mempunyai nilai berkisar antara -1 dan 1 $(-1 \leqslant r \leqslant 1)$, dengan semakin besar nilai $r$ berarti semakin erat hubungan linier kedua peubah tersebut. Ketentuan yang tepat mengenai apakah angka korelasi tertentu menunjukkan tingkat korelasi yang tinggi atau lemah sebenarnya tidak ada ketentuan yang tegas, tetapi Santoso (2001) memberikan pedoman yang sederhana, bahwa angka korelasi di atas 0.50 menunjukkan korelasi yang cukup kuat, sedangkan di bawah 0.50 menunjukkan korelasi yang lemah.

Berdasarkan pernyataan di atas, maka peubah yang berkorelasi nyata dengan jumlah spora adalah kandungan $\mathrm{P}$ tersedia. Hal ini menunjukkan bahwa adanya hubungan yang erat antara jumlah spora dengan kandungan $P$ tersedia, dimana ditunjukkan dengan nilai $r=-0.55$ dan $P<0.05$. Untuk peubah lainnya bentuk korelasi yang terjadi tidak nyata $(\mathrm{r}<0.50$ dan $\mathrm{P}>0.05)$, walaupun ada kecenderungan keterkaitan antara jumlah spora dengan topografi, kadar air dan kadar liat. Pola hubungan antara jumlah spora dan P tersedia, disajikan pada Gambar 1. 


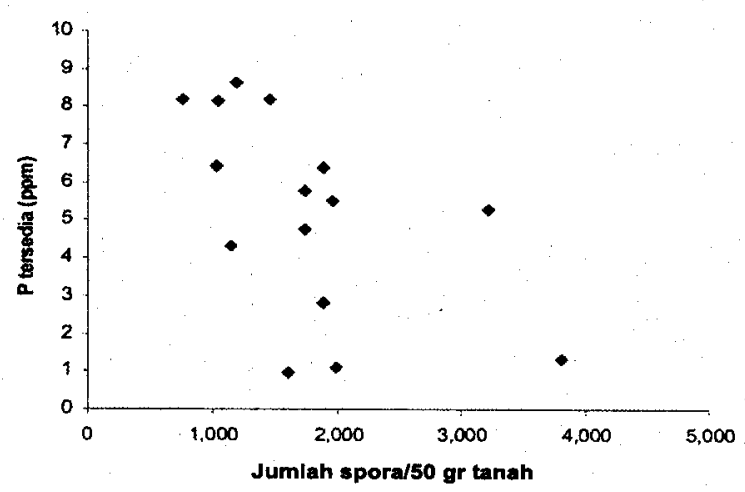

Gambar 1. Pola hubungan negatif antara jumlah spora dengan $P$ tersedia

Pada Gambar 1 terlihat pola hubungan linier yang terjadi adalah negatif, yaitu adanya titik-titik pengamatan yang menggerombol mengikuti garis lurus dengan kemiringan negatif, kecenderungan jumlah spora menurun selaras meningkatnya kandungan $P$ tersedia. Korelasi ini menunjukkan bahwa jumlah spora CMA mempunyai keterkaitan yang erat dengan kondisi tanah (dalam hal ini P tersedia). Seperti telah diuraikan sebelumnya, $P$ merupakan unsur makro yang sangat dibutuhkan tanaman dan memiliki peran utama didalam mentransfer energi yang diperlukan dalam kegiatan metabolisme tanaman. Keterkaitan $P$ tersedia dengan jumlah spora, tentu tidak terlepas dari peranan tanaman inang, karena CMA merupakan cendawan yang bersifat obligat dengan tanaman inang. Fenomena yang menunjukkan adanya hubungan negatif antara jumlah spora dengan $\mathrm{P}$ tersedia, selaras dengan teori pembentukan mikoriza yang dikemukakan Hatch (1937) dalam Imas et al. (1989) dengan teori mikrotrofinya yang menyebutkan mikoriza akan terbentuk jika terdapat ketidakseimbangan di dalam ketersediaan satu atau lebih dari 4 unsur hara makro yaitu N, P, K dan Ca. Bjorkman (1942) dalam Imas et al. (1989) dengan teori karbohidrat, dimana disebutkan mikoriza akan berkembang dengan baik, jika tumbuhan mendapat cahaya $25 \%$ lebih dari cahaya siang penuh dan status unsur hara dalam sedikit defesiensi dalam unsur $\mathrm{N}$ atau $\mathrm{P}$, dimana disebutkannya ketersediaan $\mathrm{N}$ dan $\mathrm{P}$ yang tinggi akan dapat menurunkan produksi karbohidrat, sehingga dapat menurunkan pembentukan mikoriza. Smith dan Read (1997) menjelaskan mekanisme pembentukan spora, disebutkannya ekternal hifa merupakan bagian terpenting didalam produksi spora sehingga didalam pembentukan spora, hifa eksternal harus mendapatkan pasokan karbohidrat dalam jumlah yang memadahi. Berdasarkan pernyataan tersebut maka teori karbohidrat mendukung, yaitu kandungan $P$ tersedia dalam jumlah cukup akan menurunkan produksi karbohidrat yang pada akhimya mempengaruhi sporulasi spora.

Douds dan Schenk (1990) dalam Smith dan Read (1997) menemukan populasi spora pada beberapa cendawan juga menurun ketika kandungan hara cukup baik dibandingkan pada saat terjadinya defisiensi hara khususnya P. Smith dan Read (1997) menjelaskan hal yang sama pada kosentrasi hara yang rendah mengakibatkan meningkatnya persen kolonisasi antara tanaman dan cendawan, yang mungkin akan meningkatkan kolonisasi pada akar dan produksi spora. Selain itu memang cendawan mikoriza bersifat oportunis ekonomis, pada kondisi tingkat kesuburan baik, maka cendawan mikoriza tidak akan menjadi aktif. Kondisi ini tentu berkaitan dengan sifat simbiosis mutualistik, dimana pada saat kesuburan tanah baik maka tidak ada kebutuhan tanaman untuk meminta bantuan dengan cendawan mikoriza.

Berdasarkan beberapa pernyataan di atas membuktikan ada hubungan linier antara jumlah spora dengan kandungan $P$ di dalam tanah. Jeffries et al. (2003) bahkan melaporkan CMA memegang peranan penting didalam siklus $P$, terutama didalam meningkatkan laju pelarutan bentuk-bentuk $P$ yang tidak tersedia dan meningkatkan laju serapan $P$ oleh tanaman. Hal ini berkaitan dengan beberapa kemampuan yang dimiliki CMA diantaranya pertama, menghasilkan berbagai macam asam organik yang dapat 
melarutkan fosfor dari bentuk tidak tersedia (P-Al, P-Fe dan P-Ca) menjadi tersedia, kedua, melarutkan dan menyerap fosfor yang tersekap dalam struktur tanah yang tidak dapat ditembus dan dijangkau akar, ketiga, menyerap fosfor yang tidak terjangkau dari perakaran dan tidak dapat berdifusi ke akar karena minimnya lengas tanah dan keempat menyerap semua bentuk fosfor (organik dan anorganik) dan menyimpannya dalam tubuh cendawan sehingga terhindar dari adsorpsi mineral sekunder atau alih bentuk (transformation) P lainnya serta kelima, meningkatkan kesehatan tanaman dengan cara melindunginya dari serangan patogen, meningkatkan serapan air, penyediaan zat-zat pengatur tumbuh, meningkatkan aktivitas mikoorganisme dan melindungi tanaman dari bahaya keracunan logam berat. Dengan demikian kehadiran CMA sangatlah penting, terutama dalam merehabilitasi lahan yang ditumbuhi oleh

\section{KESIMPULAN}

1. Kondisi tanah di lokasi penelitian secara umum tidak subur yang ditunjukkan dengan $\mathrm{pH}$ tanah yang masam $(4,5)$, bahan organik yang rendah sampai dengan sedang, yaitu C-organik $(215 \%)$, kandungan $\mathrm{N}$ total $(0,13 \%)$ P tersedia (498 ppm), K tersedia $(0,44 \mathrm{me} / \mathrm{g})$ dan KTK $(8,99 \mathrm{me} / 100 \mathrm{~g}$.

2. Kepadatan spora CMA di lokasi penelitian cukup baik, dengan jumlah spora $1288-2321$ spora/50 gr pada bulan kering dan pada bulan basah 1274-2163 spora/50 gr tanah, dari genus Glomus, Acaulospora dan Scutellospora.

3. Adanya korelasi negatif antara jumlah spora dengan kandungan $P$ tersedia, dimana jumlah spora menurun selaras dengan meningkatnya kandungan $P$ tersedia di dalam tanah.

\section{DAFTAR PUSTAKA}

Badan Planologi Kehutanan. 2002. Indikasi Kawasan Hutan dan Lahan Yang Perlu Dilakukan Rehabilitasi. Jakarta: Departemen Kehutanan, Badan Planologi Kehutanan.

Bagyaraj DJ. 1991: Ecology of Vesicular-Arbuscular Mycorrhizae. Di dalam: Hand Book of Applied Mycology Vol 1: Soil and Plant. New York-Basel-Hongkong. Marcel Dekker, Inc.

Brundrett M, Boucher N, Dell NB, Grove T, Malajczuk N. 1994. Working with Mycorrhizas in Forestry and Agriculture. Di dalam: International Mycorrhizal Workshop. Kaiping China.

Hardjowigeno S. 1993. Klasifikasi Tanah dan Pedogenesis. Jakarta. Akademika Pressindo.

INVAM. 2003. International Culture Collection of (Vescular) Arbusular Mycorrhizal Fungi.http:// www.invam.caf.wvu.edu/mycoinfor/taxonomy/classification.htm.(20 Maret 2004).

Imas TRS Hadioetomo, Gunawan AW, Setiadi Y. 1989. Mikrobiologi Tanah. Bogor: IPB, Pusat Antar Universitas Bioteknologi.

Jalali BL, Jalali I. 1991. Mycorrhiza in Plant Disease Control. Di dalam: Hand Book of Applied Mycology Vol 1: Soil and Plant. New York-Basel-Hongkong. Marcel Dekker, Inc.

Jeffries P, Dodd JC. 1991. The Use of Mycorrhizal Inoculants in Forestry and Agriculture. Di dalam: Hand Book of Applied Mycology Vol 1: Soil and Plant. New York-Basel- Hongkong. Marcel Dekker, Inc. 
Jeffries P, Gianinazzi S, Perotto S, Turnau K, Barca JM. 2003. The Contribution of Arbuscular Mycorrhizal Fungi in Sustainable Maintenance of Plant Health and Soil Fertility. Biol. Fertil. Soils 37: 1-16.

Koide RT, Mosec B. 2004. A History of Reseach on Arbuscular Mycorrhiza. Mycorrhiza.

Mackinnon K, Hatta G, Halim H, Mangalik A. 2000. Ekologi Kalimantan. Seri Ekologi Indonesia Buku III. Jakarta. Prenhallindo.

Mansur I, Setiadi Y, Primaturi R. 2002. Status of Research on Mycorrhiza Arbuscula Associated with Tropical Tree Species. Paper Presented at The Fourth International Wood Science Symposium LIPI-JSPS Core University Program in The Field of Wood Science. Tanggerang, Indonesia. Rescarch Center of Physics Indonesian Institute of Science.

Mattjik AA, Sumertajaya IM. 2000. Rancangan Percobaan. Bogor. IPB Press.

Mueller D, Ellenberg. 1974. Aims and Methods of Vegetation Ecology. New York, London, Sydney, Toronto. John Wiley \& Son, Inc.

Pacioni G. 1992. Wet Sieving and Decanting Techniques for the Extraction of Spores of VA mycorrhizal Fungi. Di dalam: Methods in Microbiology. San Diego. Academic Press Inc.

Paulitz TC, Linderman RG. 1991. Mycorrhizal Interactions With Soil Organisms. Di dalam: Hand Book Of Applied Mycology Vol 1: Soil and Plant. New York-Basel- Hongkong. Marcel Dekker, Ine.

Smith SE, Read DJ. 1997. Mycorrhizal Simbiosis. $2^{\text {nd }}$ Edition. San Diego-London-New York-BostonSydney-Tokyo-Toronto. Academic Press. Harcourt Brace \& Company, Publisher.

Santoso S. 2001. SPSS Versi 10 Mengolah Data Statistik Secara Profesional. Jakarta. PT. Elex Media Komputindo Gramedia.

Sarief .E.S. 1986. Ilmu Tanah Pertanian. Bandung. Pustaka Buana.

Schmidt, F.H dan J.H.A. Ferguson, 1951. Rainfall types based on wet and dry period ratios for Indonesia with Western New Guinea Verhand. No.42. Kementrian Perhubungan, Djawatan Meteorologi dan Geofiska, Jakarta.

Soerianegara I, Indrawan A. 1998. Ekologi Hutan Indonesia. Bogor: IPB, Fakultas Kehutanan.

Sunyoto RB, Suparmi, Suwardjo. 1993. Inventarisasi dan Delinasi Lahan Kritis di Propinsi Sulawesi Tenggara. Prosiding Penelitian Tanah dan Agroklimat No. 10. Bogor. Puslittanak.

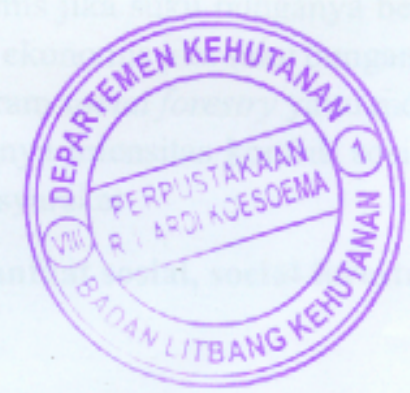

